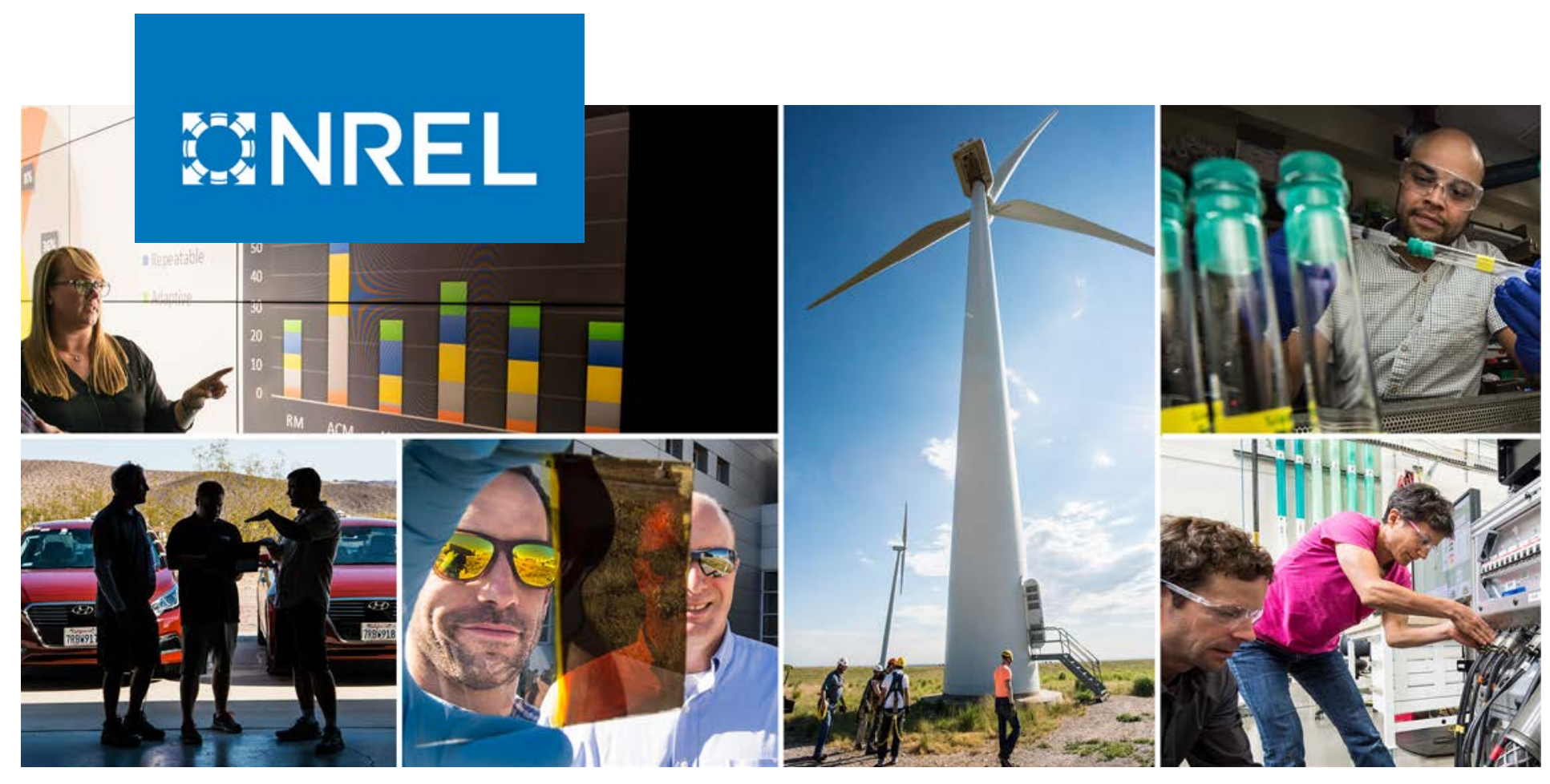

\title{
Water and Climate Impacts on ERCOT Long-Term Systems Assessment
}

Stuart Cohen, ${ }^{1}$ Ariel Miara, ${ }^{1}$ Vincent Tidwell, ${ }^{2}$ Sean Turner, ${ }^{3}$ Nathalie Voisin, ${ }^{3}$ and Ana Dyreson ${ }^{1}$

1 National Renewable Energy Laboratory

2 Sandia National Laboratories

3 Pacific Northwest National Laboratory

NREL is a national laboratory of the U.S. Department of Energy Office of Energy Efficiency \& Renewable Energy

Operated by the Alliance for Sustainable Energy, LLC

This report is available at no cost from the National Renewable Energy Laboratory (NREL) at www.nrel.gov/publications.
Technical Report

NREL/TP-6A20-79581

January 2022 


\title{
GNREL
}

\section{Water and Climate Impacts on ERCOT Long-Term Systems Assessment}

\author{
Stuart Cohen, ${ }^{1}$ Ariel Miara, ${ }^{1}$ Vincent Tidwell, ${ }^{2}$ \\ Sean Turner, ${ }^{3}$ Nathalie Voisin, ${ }^{3}$ and Ana Dyreson ${ }^{1}$
}

1 National Renewable Energy Laboratory

2 Sandia National Laboratories

3 Pacific Northwest National Laboratory

\section{Suggested Citation}

Cohen, Stuart, Ariel Miara, Vincent Tidwell, Sean Turner, Nathalie Voisin, and Ana Dyreson. 2022. Water and Climate Impacts on ERCOT Long-Term Systems Assessment. Golden, CO: National Renewable Energy Laboratory. NREL/TP-6A20-79581.

https://www.nrel.gov/docs/fy22osti/79581.pdf.

NREL is a national laboratory of the U.S. Department of Energy Office of Energy Efficiency \& Renewable Energy Operated by the Alliance for Sustainable Energy, LLC

This report is available at no cost from the National Renewable Energy Laboratory (NREL) at www.nrel.gov/publications.

Contract No. DE-AC36-08GO28308
Technical Report

NREL/TP-6A20-79581

January 2022

National Renewable Energy Laboratory 15013 Denver West Parkway Golden, CO 80401

303-275-3000 • www.nrel.gov 


\section{NOTICE}

This work was authored in part by the National Renewable Energy Laboratory, operated by Alliance for Sustainable Energy, LLC, for the U.S. Department of Energy (DOE) under Contract No. DE-AC36-08GO28308. This work was also authored in part by Sandia National Laboratories under Contract DE-NA-0003525 and by Pacific Northwest National Laboratory under Contract DE-AC05-76RLO1830. Funding provided by the U.S. Department of Energy Office of Electricity Delivery and Energy Reliability. The views expressed herein do not necessarily represent the views of the DOE or the U.S. Government or ERCOT.

This report is available at no cost from the National Renewable Energy Laboratory (NREL) at www.nrel.gov/publications.

U.S. Department of Energy (DOE) reports produced after 1991 and a growing number of pre-1991 documents are available free via www.OSTI.gov.

Cover Photos by Dennis Schroeder: (clockwise, left to right) NREL 51934, NREL 45897, NREL 42160, NREL 45891, NREL 48097, NREL 46526.

NREL prints on paper that contains recycled content. 


\section{Acknowledgments}

This work was authored in part by the National Renewable Energy Laboratory, operated by Alliance for Sustainable Energy, LLC, for the U.S. Department of Energy (DOE) under Contract No. DE-AC36-08GO28308. This work was also authored in part by Sandia National Laboratories under Contract DE-NA-0003525 and by Pacific Northwest National Laboratory under Contract DE-AC05-76RLO1830. The Electric Reliability Council of Texas (ERCOT) also advised on the execution of this work and reviewed this report. The authors would also like to thank Julie Jin, Pete Warnken, Melissa Pauley, Daniel Steinberg, and Jaquelin Cochran for reviewing this work prior to publication. Funding was provided by the U.S. Department of Energy Office of Electricity Delivery and Energy Reliability. The views expressed in the article do not necessarily represent the views of the DOE or the U.S. Government or ERCOT. The U.S. Government retains and the publisher, by accepting the article for publication, acknowledges that the U.S. Government retains a nonexclusive, paid-up, irrevocable, worldwide license to publish or reproduce the published form of this work, or allow others to do so, for U.S. Government purposes. 


\section{List of Acronyms}

$\mathrm{AC}$

AEO

ATB

BA

CAES

$\mathrm{CC}$

CCS

CT

EIA

ERCOT

GCM

GW

IGCC

ISI-MIP

ITC

LTSA

$\mathrm{m}^{2}$

MWh

NREL

O\&M

PV

PTC

RCP

$\mathrm{RE}$

ReEDS

RPG

SNL

TC

TWh

W

WBM
Alternating Current

Annual Energy Outlook

Annual Technology Baseline

Balancing Area

Compressed Air Energy Storage

Combined-Cycle

Carbon Capture and Sequestration

Combustion Turbine

Energy Information Administration

Electric Reliability Council of Texas

Global Climate Model

Gigawatt

Integrated Gasification Combined Cycle

Inter-Sectoral Impact Model Intercomparison Project

Investment Tax Credit

Long-Term System Assessment

Square meters

Megawatt-Hour

National Renewable Energy Laboratory

Operation and Maintenance

Photovoltaic

Production Tax Credit

Representative Concentration Pathway

Renewable

Regional Energy Deployment System

Resource Planning Group

Sandia National Laboratories

Tax Credit

Terawatt-Hour

Watts

Water Balance Model 


\section{Executive Summary}

Water and climate change pose many potential challenges to the electric power system. Substantial water is withdrawn every day to support thermoelectric power generating unit operations, and changes to water supply have the potential to affect generation dispatch. Climate change can accelerate growing demand for electricity, which can necessitate additional generating capacity, often in locations with limited water supply. Drought conditions can also lead to reduced output at thermoelectric power plants due to streamflow and reservoir levels dropping below intake structures, or water temperatures exceeding a power plants' permitted operating conditions. Here we explore how future climate change might influence decisions related to electricity capacity expansion planning in Electric Reliability Council of Texas (ERCOT) using a multi-model framework. Specifically, water resource modeling is used to simulate climate impacts on the future water supply for thermoelectric and hydropower generation for four future climate projections. Separately, temperature impacts on electricity load are evaluated for these scenarios. These climate impacts are applied to five alternative electricity futures in an electricity capacity expansion model that projects future generation and transmission capacity additions in ERCOT through 2034. Results indicate that climate change could have a measurable influence on future generation and transmission capacity needs; we find that temperature-driven increases in peak and average load result in 5-15 GW additional generating capacity and up to $1 \mathrm{GW}$ additional transmission capacity depending on climate scenario and future electricity mix. Additional capacity is comprised of a mix of PV, natural gas, and wind, with shares depending on the makeup of economic, policy and technology assumptions. Climate impacts increase total system costs $2-5 \%$, while the marginal cost of energy and emissions are not affected substantially by climate change effects. 


\section{Table of Contents}

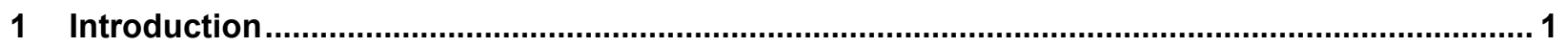

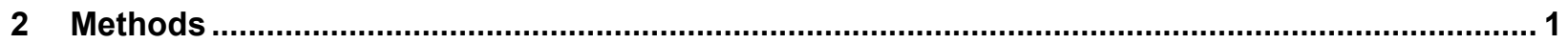

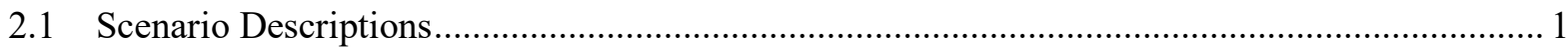

2.2 Capacity Expansion Planning Platform...................................................................... 2

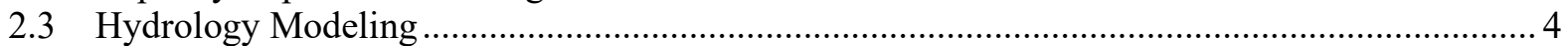

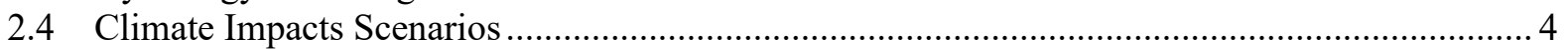

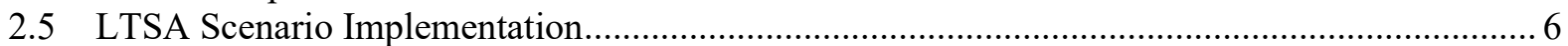

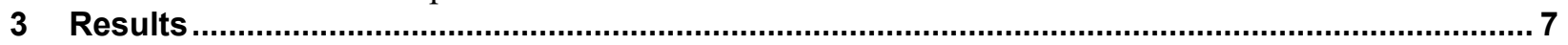

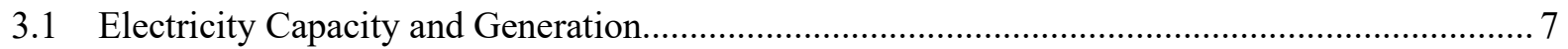

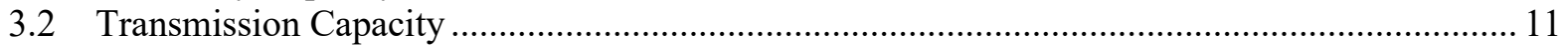

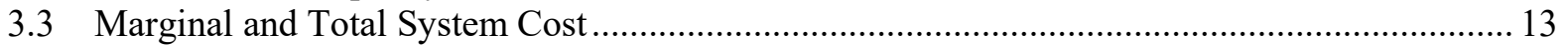

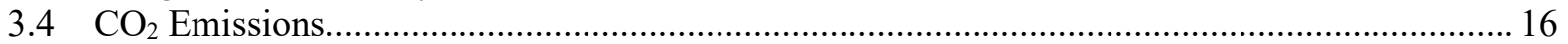

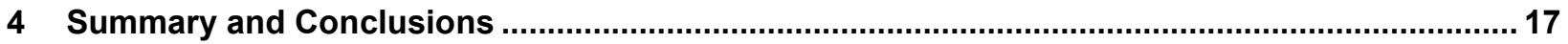

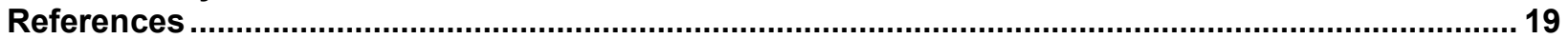




\section{List of Figures}

Figure 1. ReEDS model spatial resolution for ERCOT with the modeled aggregated transmission network shown.

Figure 2. Change in load across ERCOT in each climate impact scenario, along with an average. Values are based on heating and cooling degree days form the WBM-adjusted ISI-MIP air temperature projections.

Figure 3. Water availability for power capacity in ERCOT in each climate impact scenario, along with an average. Values use WBM adjustments to baseline Sandia National Laboratories (SNL) data. (note: $y$-axis does not start at zero) .

Figure 4. ERCOT capacity expansion in each LTSA electricity scenario under static historical climate conditions. $[\mathrm{PV}=$ solar photovoltaic, with $\mathrm{AC}$ referring to the Alternating Current-connected capacity; $\mathrm{CSP}=$ concentrated solar power; $\mathrm{CT}=$ combustion turbine; $\mathrm{CC}=$ combined cycle; $\mathrm{CCS}=$ carbon capture and sequestration; IGCC $=$ integrated gasification combined cycle] $\ldots 8$

Figure 5. Climate impacts on ERCOT 2034 capacity for each climate scenario relative to the corresponding electricity scenario without climate change impacts. Circles on plot represent net effect.

Figure 6. ERCOT generation expansion in each LTSA electricity scenario under static historical climate conditions

Figure 7. Climate impacts on ERCOT 2034 generation for each climate scenario relative to the corresponding electricity scenario without climate change impacts. Circles on plot represent net effect.

Figure 8. ERCOT transmission capacity over time in historical climate scenarios. Note: $y$-axis does not start at 0 .

Figure 9. Change in 2034 ERCOT transmission capacity for climate impacts scenarios, relative to the corresponding historical climate scenario.

Figure 10. Net present value of total system investment and operating costs in 2018-2034 for historical climate scenarios. Conventional refers to fossil and nuclear. Water refers to water access purchases for new capacity.

Figure 11. The change in total system investment and operating costs in 2018-2034 in climate impacts scenarios relative to the corresponding historical climate scenario. Conventional refers to fossil and nuclear. Water refers to water access purchases for new capacity.

Figure 12. ERCOT-average marginal cost of electrical energy over time in all scenarios. This metric is the marginal price taken from the electricity supply-demand balance in ReEDS. Note that the yaxis does not start at 0 and costs are similar through 2020 because the capacity changes are largely prescribed in historic and current years.

Figure 13. Electric sector $\mathrm{CO}_{2}$ emissions over time for all scenarios.

\section{List of Tables}

Table 1. ReEDS Scenario Descriptions. 


\section{Introduction}

By law, the Electric Reliability Council of Texas, Inc. (ERCOT) is required to study the need for increased transmission and generation capacity on a bi-annual schedule. This planning process considers both additions and upgrades to system infrastructure to help maintain system reliability and efficiency. Planning considers both a near-term (six year) and a long-term (15 year) planning horizon. Many factors play into the associated analysis including changing load profiles, cost of generation technologies, cost of fuels, regulation and environmental policies. An issue of growing importance is water quality and availability and how it might change with climate.

Water can pose many challenges to ERCOT's electric power system. In Texas, more than 131 billion gallons of fresh and saline water were withdrawn every day to support various unit operations (e.g., steam cycle makeup water, air scrubbers, cooling water) for thermoelectric power generation (Dieter et al. 2018). Demand for electricity is growing, and with it can come the need to site new capacity, often in locations with limited water supply (Averyt et al. 2013; Tidwell et al. 2016; Miara et al. 2019). Drought conditions can also constrain thermoelectric power plant operations due to streamflow and reservoir levels dropping below intake structures (Turner et al. 2021), or water temperatures exceeding a power plants' permitted operating conditions (McCall et al. 2016).

The state's water resources are also subject to changing climate conditions, which could similarly impact the electric grid (Voisin et al. 2020). Climate change will influence electricity loads and are expected to increase summer peak demand and decrease winter demand (Dirks et al 2015; Sathaye et al. 2013; Allen et al. 2016; Auffhammer et al. 2017). Increasing temperatures will reduce the maximum capacity of transmission lines (Bartos et al 2016; Sathaye et al. 2013), transformers and substations (Sathaye et al. 2013) while also reducing the efficiency of power conversion and thermal cooling (Chuang and Sue 2005; Durmayaz and Sogut 2006; Ibrahim et al. 2014). Climate change will impact stream flows, possibly resulting in more frequent droughtlike conditions with limited water supply or elevated stream temperatures (Bartos and Chester 2015; Van Vliet et al. 2012; Miara et al 2017; Miara et al. 2018; Henry and Pratson 2016; Henry and Pratson 2019). Changing climate will also impact the availability of water for new capacity development and thus challenge the siting of new thermoelectric generation (Roy et al. 2012; Sovacool and Sovacool 2009).

Here we describe a study that explicitly incorporates water and climate related factors into ERCOT's Long-Term System Assessment (LTSA) approach. Specifically, we report on the results of capacity expansion modeling that introduces long-term temperature and water availability projections and is constrained by the availability of water for siting new thermoelectric generation.

\section{Methods}

\subsection{Scenario Descriptions}

ERCOT studies different scenarios as part of its LTSA planning process to account for the inherent uncertainty in future environmental, technological and regulatory conditions. The goal of using scenarios in the LTSA is to identify upgrades that are robust across a range of 
alternative futures. Scenarios are developed by members of the ERCOT Regional Planning Group (RPG). Through a series of stakeholder-driven workshops five scenarios were adopted:

- Current Trends;

- High Economic Growth;

- High Renewable (RE) Penetration;

- High Renewable (RE) Cost; and

- Emerging Technology.

These five scenarios were implemented in the capacity expansion planning platform described below using consistent input data and assumptions with ERCOT scenario definitions whenever possible. This scenario implementation is also described below.

Uncertainty in future climate makes it useful to assess climate change impacts using a range of alternative scenarios that capture possible future climate conditions. The Climate Model Intercomparison Project (CMIP) provides a large dataset from which to select such conditions (ESFG-LLNL 2021). While some analyses might use averages across climate model projections to draw insights, we instead choose four alternative climate futures to project a range of potential impacts on electricity demand and water supply for thermoelectric and hydroelectric generation. The four climate projections were selected to span a broad range of projected impacts of climate change on temperature and water availability trends in the Western U.S., while maintaining internal consistency by considering each scenario individually. Selected global climate model (GCM) projections included IPSL-CM5A-LR for representative concentration pathway (RCP) of $4.5 \mathrm{~W} / \mathrm{m}^{2}$ radiative forcing (median global warming projection) (IPSL45), GFDL-ESM2M RCP4.5 (GFDL45), and for $8.5 \mathrm{~W} / \mathrm{m}^{2}$ radiative forcing (high global warming projection) IPSLCM5A-LR for RCP8.5 (IPSL85), and MIROC-ESM-CHEM RCP8.5 (MIROC85). See Section 2.4 for additional details. While Western U.S. outcomes were used to choose these four climate projections, future work for ERCOT would benefit from a climate scenario selection approach focused specifically on Texas climate outcomes. Water-climate impacts are identified by also simulating each LTSA scenario under static historical climate conditions.

\subsection{Capacity Expansion Planning Platform}

Capacity expansion planning is modeled using the National Renewable Energy Laboratory (NREL) Regional Energy Deployment System (ReEDS). ReEDS is an electric sector capacity expansion model for the contiguous U.S. that minimizes the cost of investment and operation for electricity generation, transmission, and storage through a future year up to 2050 (Cohen et al. 2019). Since its inception in 2003 it has been used in a multitude of analyses exploring future renewable energy deployment, policies, and climate-water impacts (Miara et al. 2019; Cole et al. 2018; DOE 2016; DOE 2019; Cole et al. 2019; Frazier et al 2019; Mai et al 2019).

ReEDS is formulated as a deterministic linear program optimization, and the 2018 version employed for this analysis executes in 2-year solution time steps through a 2034 end year, chosen to align with the current ERCOT LTSA (Cohen et al. 2019). The model is executed for the contiguous U.S. to preserve any cross-interconnect electricity relationships, but this analysis focuses specifically on results within the ERCOT Interconnection. The ERCOT interconnection in ReEDS is subdivided into 7 balancing areas (BAs) for which load and generation resources are balanced, and these BAs are connected by an aggregated transmission system with capacity 
and flow constraints between each region (Figure 1). The generating fleet composition is initialized using the ABB Velocity Suite (2017) database, which also includes data for known construction and retirements. As demand and corresponding capacity and reserves needs rise over time, the model represents economic competition between a suite of generation and storage technologies and can expand transmission capacity to accommodate system needs.

ReEDS employs a reduced-form dispatch within each model year to better represent electricity cost and value streams. This dispatch formulation balances supply and demand in four chronological time slices in each season (morning, afternoon, evening, night) along with a time slice for the average of the 40 highest summer demand hours, which allows ReEDS to better capture capacity needs at peak demand. This chronological intra-annual time resolution incorporates consistent load and renewable generation profiles, opportunities for diurnal energy arbitrage, and curtailment reduction by storage systems. The impacts of the variable nature of wind and solar resources on power system operations and investment decisions is captured using detailed capacity credit calculations using 8760-hourly data, statistical estimations of curtailments, and parameterized relationships between variable renewable deployment and operating reserve requirements. This structure updates variable generator characteristics over time as the generation mix changes, allowing for a detailed regional look at electric sector investment decisions under a broad range of scenarios.

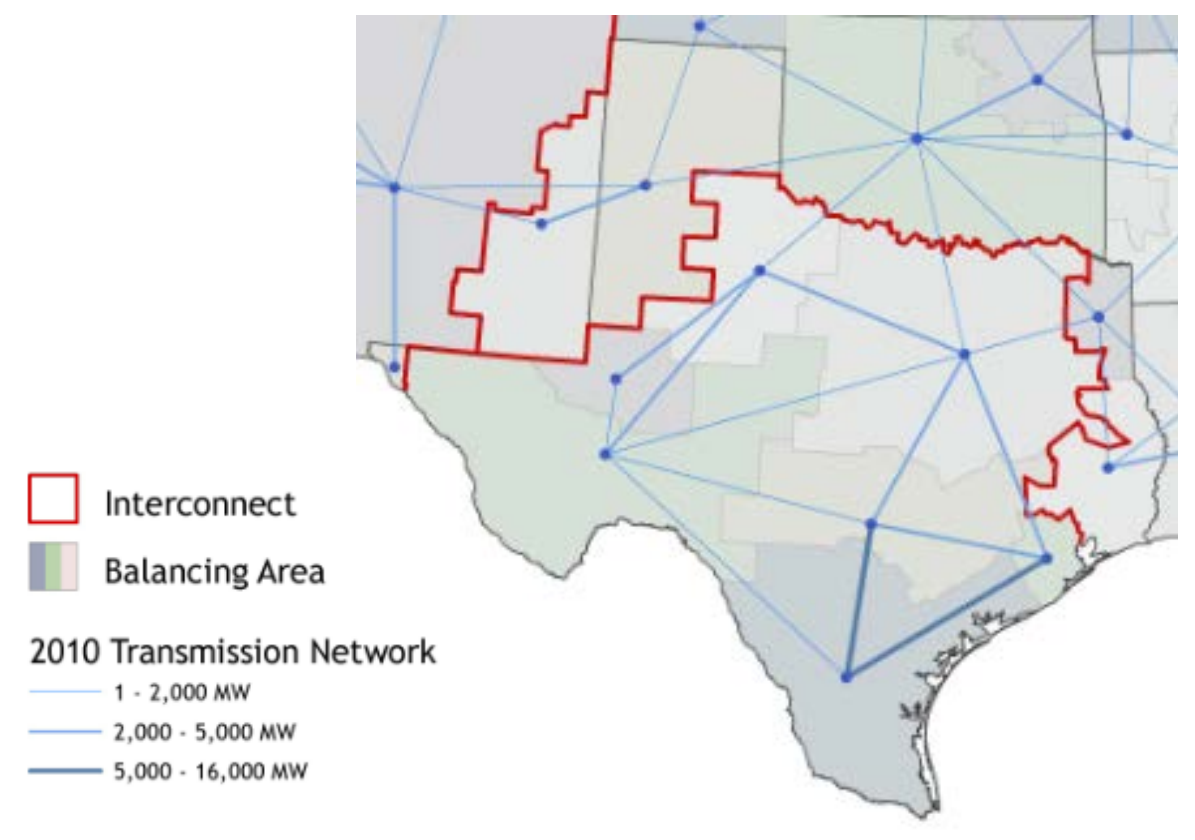

Figure 1. ReEDS model spatial resolution for ERCOT with the modeled aggregated transmission network shown.

Climate change impacts are endogenously represented in ReEDS in several ways. For temperature impacts, the model uses heating and cooling degree data, following the one-way coupling approach detailed in Miara et al. 2019, to represent temperature impacts on electricity load and power system performance. Electricity load impacts use regressed sensitivities of load to temperature based on Sullivan et al. (2015) and McFarland et al. (2015), accounting for differences in temperature sensitivity across regions and time-of-day. Transmission capacity and power generation capacity and efficiency are also reduced for thermal generators during summer 
afternoon time slices using relationships developed by ICF (1995) and Jaglom and others (2014), though previous work finds these relationships to have little effect on capacity expansion results (Steinberg et al. 2020).

The heating and cooling degree-day information is used to adjust heat-rate and capacity at thermal power plants in addition to estimates of electricity demand and constraints on transmission. Heating and cooling degree days are calculated based on air temperature results and determine electricity demand and transmission capacities within ReEDS. The day is considered a cooling degree day if the average temperature per balancing area is greater than $20^{\circ} \mathrm{C}$ and a heating degree day if below $20^{\circ} \mathrm{C}$ (equations that describe this approach can be found in Miara et al. 2019).

Changes to water availability for thermal cooling and hydropower in ERCOT utilize runoff and river discharge outputs from the Water Balance Model (WBM) (Miara et al. 2019)., with results aggregated to ReEDS spatial and temporal resolution (see below). Thermal cooling water availability impacts are applied as constraints on surface water availability that limit the quantity of water withdrawn across the thermal generating fleet for each season and BA (Miara et al. 2019). Availability and cost of alternative sources of water (e.g., groundwater, wastewater) are provided by Tidwell and others (2014). These constraints then limit electricity generation potential according to reduced water availability. Similarly, seasonal energy availability for hydropower is adjusted over time with the changes to hydropower water availability assessed by WBM.

\subsection{Hydrology Modeling}

Projections of long-term change in hydropower and thermal cooling water availability for ReEDS are created by first driving WBM with climate forcing data from the Inter-sectorial Impact Model Intercomparison Project (ISI-MIP) (Hempel et al. 2013). The climate variables include air temperature, precipitation, near surface wind magnitude, solar radiation, and relative humidity. WBM simulates the freshwater balance using a vertical exchange model and river flow along channels using a horizontal water transport model (see Miara et al. 2013). It generates runoff and river discharge at a gridded 3' (approximately $5 \times 5 \mathrm{~km}$ ) resolution for each day, which is then aggregated to the ReEDS season and BA resolution, and then converted to a water availability change factor (relative to historic conditions) for use in the ReEDS model. The availability factors are used to impose seasonal limits on surface water withdrawals for each balancing area in ReEDS (see Miara et al. 2019 for equations). The factors are applied to water availability datasets developed at Sandia National Laboratories (Tidwell et al. 2014), which include water resources other than riverine freshwater that may be available for electricity generation. However, climate impacts on non-surface water are not considered.

\subsection{Climate Impacts Scenarios}

This analysis includes four alternative future climate scenarios to provide a range of possible temperature and water outcomes for the ERCOT region. These scenarios include two scenarios associated with greater warming (IPSL-CM5A-LR_RCP8p5 and MIROC-ESMCHEM_RCP8p5) and two with more moderate warming (IPSL-CM5A-LR_RCP4p5 and GFDLESM2M_RCP4p5). The RCP component of the climate scenario name refers to the representative concentration pathway resulting in $+4.5 \mathrm{~W} / \mathrm{m}^{2}$ or $+8.5 \mathrm{~W} / \mathrm{m}^{2}$ increase in radiative 
forcing in 2100 relative to pre-industrial levels. The other alphanumeric component refers to the global climate model used to generate the data. These scenarios are abbreviated throughout the rest of this report as IPSL85, MIROC85, IPSL45, and GFDL45.

Figure 2 shows the incremental change in ERCOT electricity load over time due to temperature changes in these scenarios, and Figure 3 shows the change in surface water availability for thermal cooling as well as hydropower. Load in 2034 is 10.7-13.0 TWh greater due to temperature effects, reflecting higher space cooling demand. Water availability impacts are uncertain across the four climate scenarios, with annual available water quantities in the range 14.4-27.7 trillion gallons within the pre-2034 period. An important caveat of this work is that climate impacts on load and water availability were not re-normalized to the most recent historical year, which could result in electric sector impacts being somewhat exaggerated. This limitation could be addressed in future work.

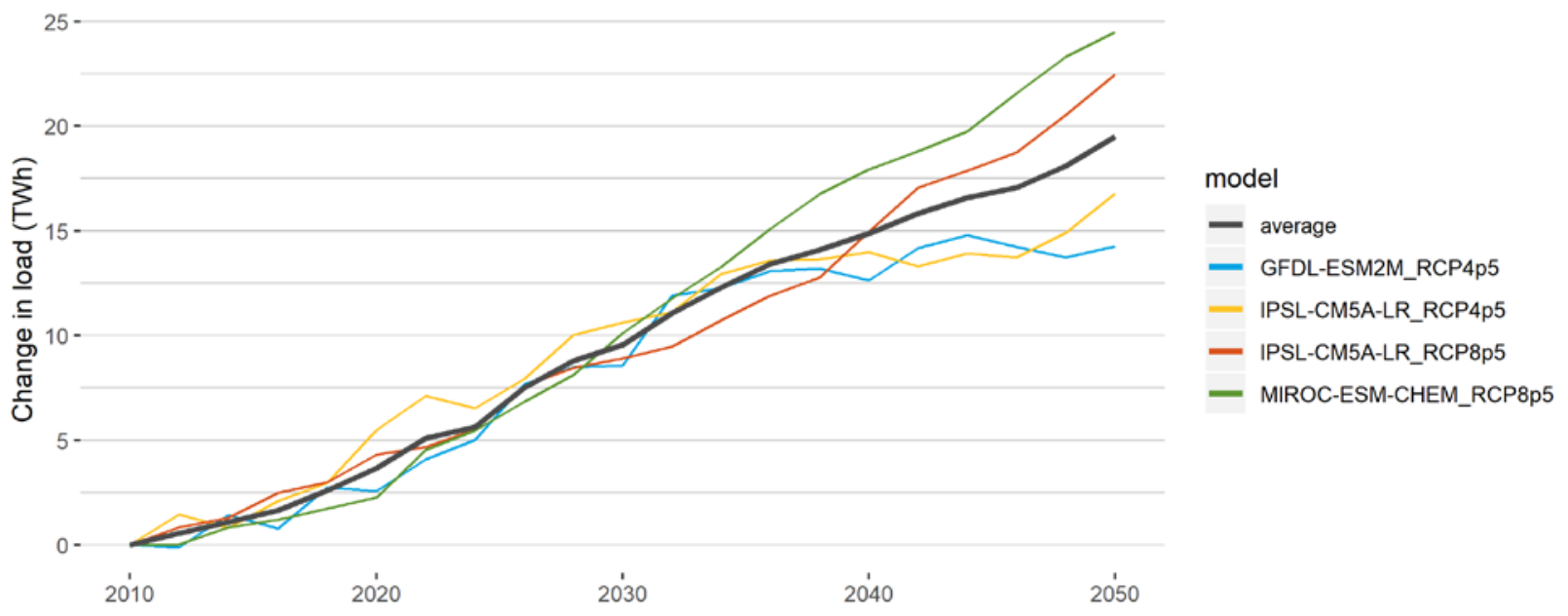

Figure 2. Change in load across ERCOT in each climate impact scenario, along with an average. Values are based on heating and cooling degree days form the WBM-adjusted ISI-MIP air temperature projections. 


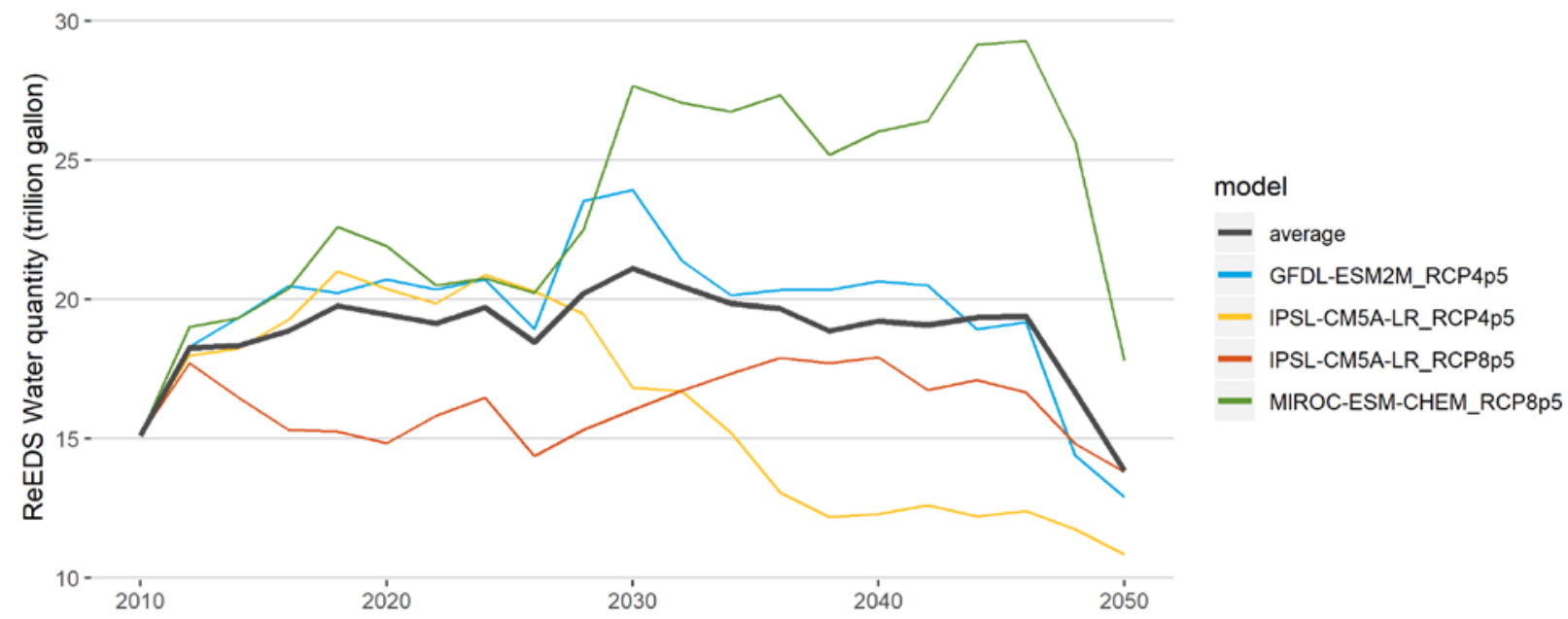

Figure 3. Water availability for power capacity in ERCOT in each climate impact scenario, along with an average. Values use WBM adjustments to baseline Sandia National Laboratories (SNL) data. (note: $y$-axis does not start at zero)

\subsection{LTSA Scenario Implementation}

Structural differences between ReEDS and ERCOT's internal planning tools require translation between the five LTSA scenario definitions used by ERCOT and the input assumptions for ReEDS. To implement ReEDS scenarios as consistently with ERCOT as possible, five classes of assumptions and data are adjusted in ReEDS as described in Table 1.

Electricity demand projections use average growth rates calculated from LTSA scenario input data, and natural gas price scenarios are aligned with the U.S. Energy Information Administration (EIA) 2018 Annual Energy Outlook (AEO18) case that matches LTSA assumptions. ReEDS technology capital and operating costs are harmonized with the LTSA in all scenarios except for the HIGH.RE.COST scenario, which instead uses the 2018 NREL Annual Technology Baseline (ATB18) High RE Cost Case for wind and solar photovoltaic (PV) cost assumptions. As with the LTSA, the HIGH.RE.PENETRATION scenario is defined by extending the renewable energy production tax credit (PTC) and investment tax credit (ITC) policies throughout the study period. Lastly, distributed rooftop PV growth scenarios are chosen from a library of deployment scenario options to best match LTSA scenario projections.

After defining these inputs, ReEDS is used to project infrastructure changes in ERCOT through 2034 for all combinations of LTSA and climate scenarios, along with a set of baseline simulations assuming historical climate conditions for each electricity scenario (designated in scenario names as HIST). The resulting 25 simulations that serve as the basis of the generation capacity and transmission results are discussed in Sections 3.1 and 3.2. 
Table 1. ReEDS Scenario Descriptions.

\begin{tabular}{|c|c|c|c|c|c|}
\hline Scenario & $\begin{array}{l}\text { Demand } \\
\text { Assumptions }\end{array}$ & $\begin{array}{l}\text { Natural Gas } \\
\text { Prices }\end{array}$ & $\begin{array}{l}\text { Technology } \\
\text { Costs }\end{array}$ & $\begin{array}{l}\text { Renewable } \\
\text { Energy } \\
\text { Incentives }\end{array}$ & $\begin{array}{l}\text { Distributed } \\
\text { PV Growth } \\
\text { Scenario }\end{array}$ \\
\hline $\begin{array}{l}\text { CURRENT. } \\
\text { TRENDS }\end{array}$ & $\begin{array}{l}\text { Current Trends } \\
\text { avg growth rate } \\
\text { from LTSA }\end{array}$ & $\begin{array}{l}\text { AEO18 High } \\
\text { OG Resource } \\
\text { Case }\end{array}$ & $\begin{array}{l}\text { ERCOT } \\
\text { LTSA }\end{array}$ & $\begin{array}{l}\text { PTC/ITC } \\
\text { Phaseout per } \\
\text { existing policy }\end{array}$ & $\begin{array}{l}\text { ATB17 High } \\
\text { RE Cost: } 0.5 \\
\text { GW in } 2034\end{array}$ \\
\hline $\begin{array}{l}\text { HIGH. } \\
\text { GROWTH }\end{array}$ & $\begin{array}{l}\text { High Growth } \\
\text { avg growth rate } \\
\text { from LTSA }\end{array}$ & $\begin{array}{l}\text { AEO18 Ref } \\
\text { Case }\end{array}$ & $\begin{array}{l}\text { ERCOT } \\
\text { LTSA }\end{array}$ & $\begin{array}{l}\text { PTC/ITC } \\
\text { Phaseout per } \\
\text { existing policy }\end{array}$ & $\begin{array}{l}\text { ATB18 High } \\
\text { TC Ext: } 3.4 \\
\text { GW in } 2034\end{array}$ \\
\hline $\begin{array}{l}\text { HIGH.RE. } \\
\text { PENETRATION }\end{array}$ & $\begin{array}{l}\text { Current Trends } \\
\text { avg growth rate } \\
\text { from LTSA }\end{array}$ & $\begin{array}{l}\text { AEO18 High } \\
\text { OG Resource } \\
\text { Case }\end{array}$ & $\begin{array}{l}\text { ERCOT } \\
\text { LTSA }\end{array}$ & $\begin{array}{l}\text { Perpetual } \\
\text { PTC/ITC }\end{array}$ & $\begin{array}{l}\text { ATB16 Low } \\
\text { Cost RE: } 24.4 \\
\text { GW in } 2034\end{array}$ \\
\hline $\begin{array}{l}\text { HIGH.RE. } \\
\text { COST }\end{array}$ & $\begin{array}{l}\text { Current Trends } \\
\text { avg growth rate } \\
\text { from LTSA }\end{array}$ & $\begin{array}{l}\text { AEO18 High } \\
\text { OG Resource } \\
\text { Case }\end{array}$ & $\begin{array}{l}\text { ATB18 High } \\
\text { RE Cost for } \\
\text { PV \& Wind }\end{array}$ & $\begin{array}{l}\text { PTC/ITC } \\
\text { Phaseout per } \\
\text { existing policy }\end{array}$ & $\begin{array}{l}\text { ATB17 High } \\
\text { RE Cost: } 0.5 \\
\text { GW in } 2034\end{array}$ \\
\hline $\begin{array}{l}\text { EMERGING. } \\
\text { TECH }\end{array}$ & $\begin{array}{l}\text { Emerging } \\
\text { Technology } \\
\text { avg growth rate } \\
\text { from LTSA }\end{array}$ & $\begin{array}{l}\text { AEO18 High } \\
\text { OG Resource } \\
\text { Case }\end{array}$ & $\begin{array}{l}\text { ERCOT } \\
\text { LTSA }\end{array}$ & $\begin{array}{l}\text { PTC/ITC } \\
\text { Phaseout per } \\
\text { existing policy }\end{array}$ & $\begin{array}{l}\text { ATB17 High } \\
\text { RE Cost: } 0.5 \\
\text { GW in } 2034\end{array}$ \\
\hline
\end{tabular}

\section{Results}

\subsection{Electricity Capacity and Generation}

Absent climate impacts, the five LTSA electricity scenarios span a range of future capacity outcomes for ERCOT (Figure 4). Coal-fired capacity is retired over time in all scenarios, but the degree varies, ranging from $11 \mathrm{GW}$ coal remaining in 2034 in the HIGH.RE.COST.HIST scenario down to $0.7 \mathrm{GW}$ remaining in the HIGH.RE.PENETRATION.HIST scenario. More notable is the difference in shares of gas-fired capacity relative to wind and PV capacity. The HIGH.RE.COST.HIST scenario has the highest share of gas-fired capacity, but the higher electricity demand in the EMERGING.TECH.HIST scenario leads to the greatest quantity of gas-fired generation at $22 \mathrm{GW}$ of natural gas-fired combustion turbines (Gas-CT) and $68 \mathrm{GW}$ of natural gas-fired combined cycle plants (Gas-CC). HIGH.RE.COST.HIST deploys relatively little PV capacity (19 GW in 2034) and actually has a net reduction in wind capacity to $12 \mathrm{GW}$ in 2034 due to capacity retired at the end of an assumed 24 year lifetime. On the other end of the spectrum, HIGH.RE.PENETRATION.HIST has $70 \mathrm{GW}$ of wind and $49 \mathrm{GW}$ PV in 2034 along with $2.7 \mathrm{GW}$ of energy storage capacity to help balance variable renewables. With CURRENT.TRENDS.HIST and HIGH.GROWTH.HIST typically having intermediate outcomes, these five scenarios thus represent a variety of possible futures from which to understand potential climate change impacts. 

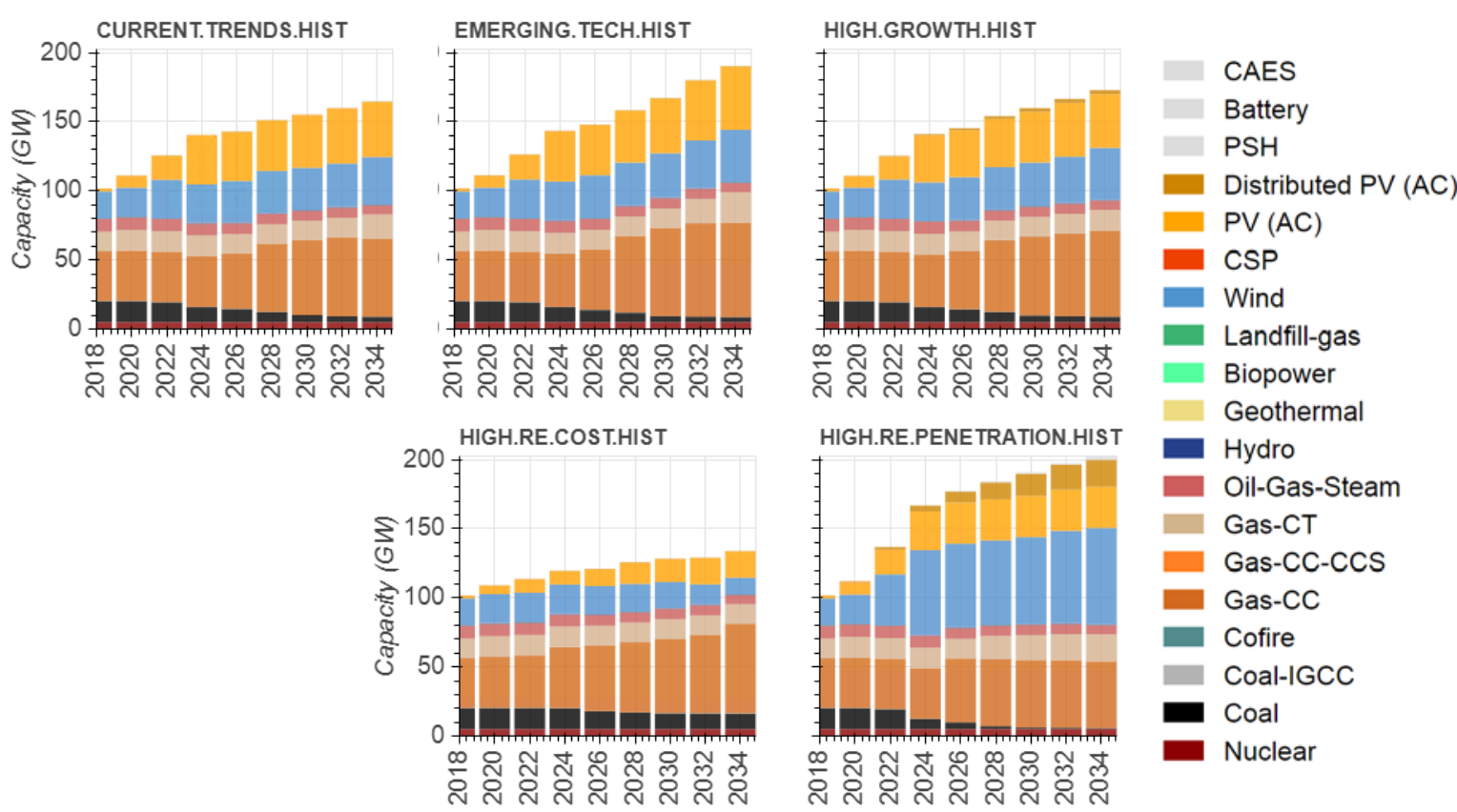

Figure 4. ERCOT capacity expansion in each LTSA electricity scenario under static historical climate conditions. [PV = solar photovoltaic, with AC referring to the Alternating Currentconnected capacity; CSP = concentrated solar power; $\mathrm{CT}=$ combustion turbine; $\mathrm{CC}=$ combined cycle; CCS = carbon capture and sequestration; IGCC = integrated gasification combined cycle]

The incremental change in capacity expansion due to climate impacts are shown in Figure 5, which plots the difference in 2034 capacity between each climate impacts scenario and the corresponding historical climate scenario. Across all scenarios, increased electricity demand from higher temperatures results in 5-15 GW of additional capacity requirements to meet system needs. Most scenarios deploy additional PV and gas-based capacity, which helps meet both energy and reserves requirements, as load is increasing more in seasons and times of day when load is already high (i.e., summer afternoons) than in lower demand time periods. This relatively higher increase in "peak" loads provides incentive for flexible technologies and those available during peak time periods.

Nevertheless, the magnitude of technology-specific impacts varies substantially across the LTSA electricity scenarios. While there is a consistent increase in Gas-CC capacity in CURRENT.TRENDS, HIGH.RE.COST, and HIGH.RE.PENETRATION, changes in Gas-CC capacity are less consistent across climate projections in the EMERGING.TECH and HIGH.GROWTH scenarios. Gas-CT capacity is several GW greater in many scenarios, but the HIGH.RE.COST and CURRENT.TRENDS scenarios have little to no need for additional GasCT capacity. While PV capacity is always higher with climate impacts, the incremental increase ranges from $0.3 \mathrm{GW}$ to $4.3 \mathrm{GW}$. Impacts on wind capacity are inconsistent even within a given electricity scenario, reflecting the complex relationships between regionally heterogeneous resources, load, and transmission.

Coal capacity is only affected in the HIGH.RE.COST scenario, which has the greatest total coal capacity in 2034. For some climate futures, coal capacity is reduced by climate impacts because the model retires coal capacity that does not meet a minimum threshold of utilization. Reduced 
coal utilization can occur due to competition from Gas-CC generation that is built in response to temperature-induced changes to the load shape.
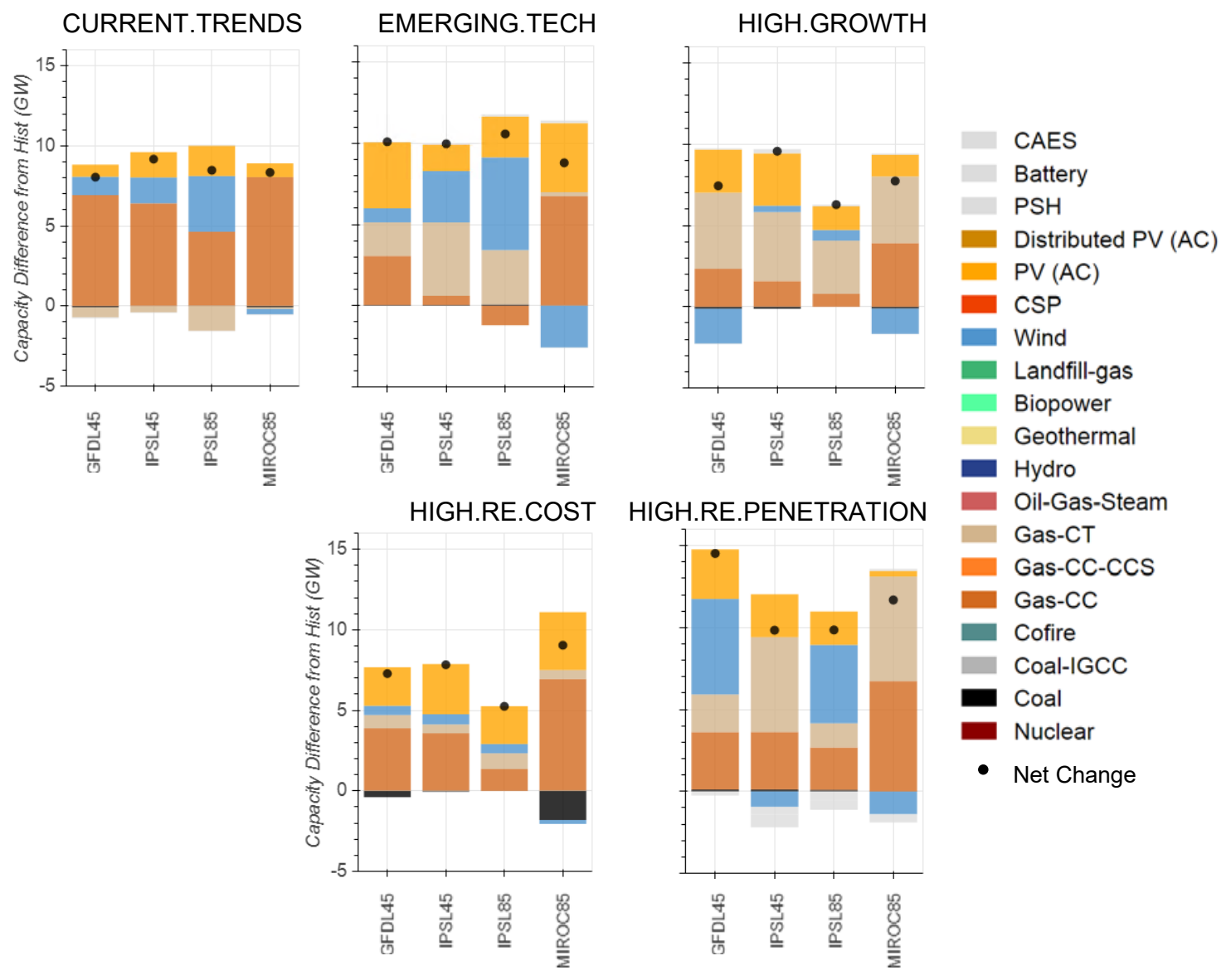

Landfill-gas

- Biopower

Geothermal

Hydro

Oil-Gas-Steam

- Gas-CT

- Gas-CC-CCS

Gas-CC

- Cofire

Coal-IGCC

- Coal

- Nuclear

- Net Change

Figure 5. Climate impacts on ERCOT 2034 capacity for each climate scenario relative to the corresponding electricity scenario without climate change impacts. Circles on plot represent net effect.

Figure 6 plots generation share by year using historical climate conditions. Trends in the generation mix follow largely from those of the capacity mix, but relative shares elucidate technology utilization and capacity factors. For example, the generation share of PV is less than the capacity share due to inherent resource availability, and the generation share of Gas-CC is typically higher. The HIGH.RE.PENETRATION.HIST scenario is notable for its high share of wind electricity, which exceeds $50 \%$ in 2034 . This outcome contrasts with the HIGH.RE.COST.HIST scenario, which is dominated by fossil and nuclear electricity with relatively little wind and PV generation. 

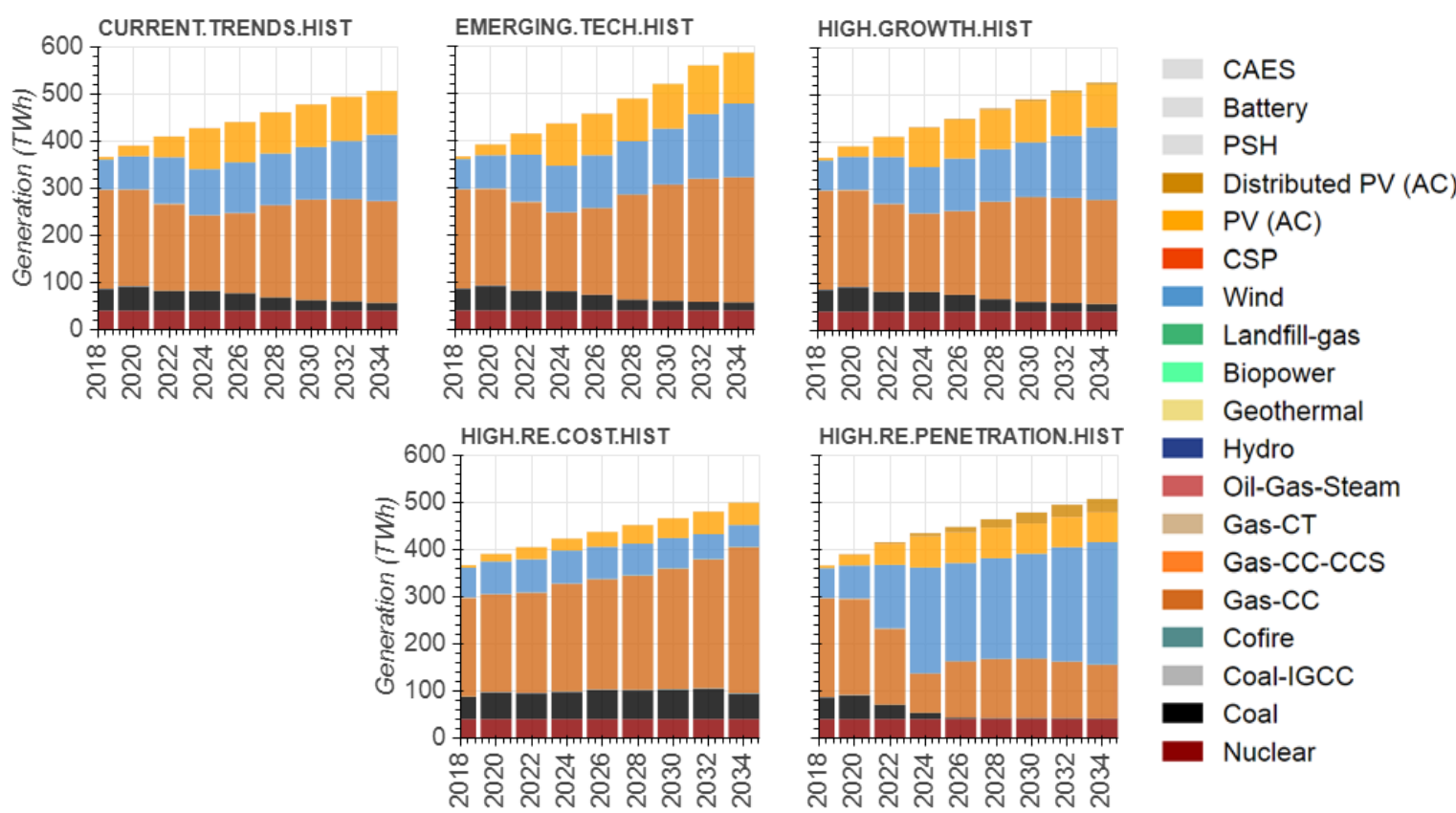

Figure 6. ERCOT generation expansion in each LTSA electricity scenario under static historical climate conditions.

Climate effects on generation, relative to historical climate scenarios, are shown in Figure 7. The consistent increase in net generation reflects higher load induced by higher temperatures, but the technology-specific response to climate change varies across both electricity and climate scenarios. Not all scenarios with an increase in Gas-CC capacity have a corresponding increase in Gas-CC generation, indicating that new Gas-CC is to some extent being built to primarily meet capacity reserve requirements. There is a negligible change to Gas-CT generation for all scenarios, demonstrating that this technology is being built exclusively to meet capacity reserve needs. Wind and PV, on the other hand, are built primarily to serve energy needs and change in generation is proportional to change in capacity by the capacity factors of these technologies. Reduced coal generation in HIGH.RE.COST is also observed in this set of results, notably for the HIGH.RE.COST.IPSL45 scenario, which does not exhibit any climate-induced change in coal capacity. This exhibits close competition between Gas-CC and coal, where Gas-CC built primarily to meet higher summer electricity demand sometimes displaces coal generation in other times of the year. 

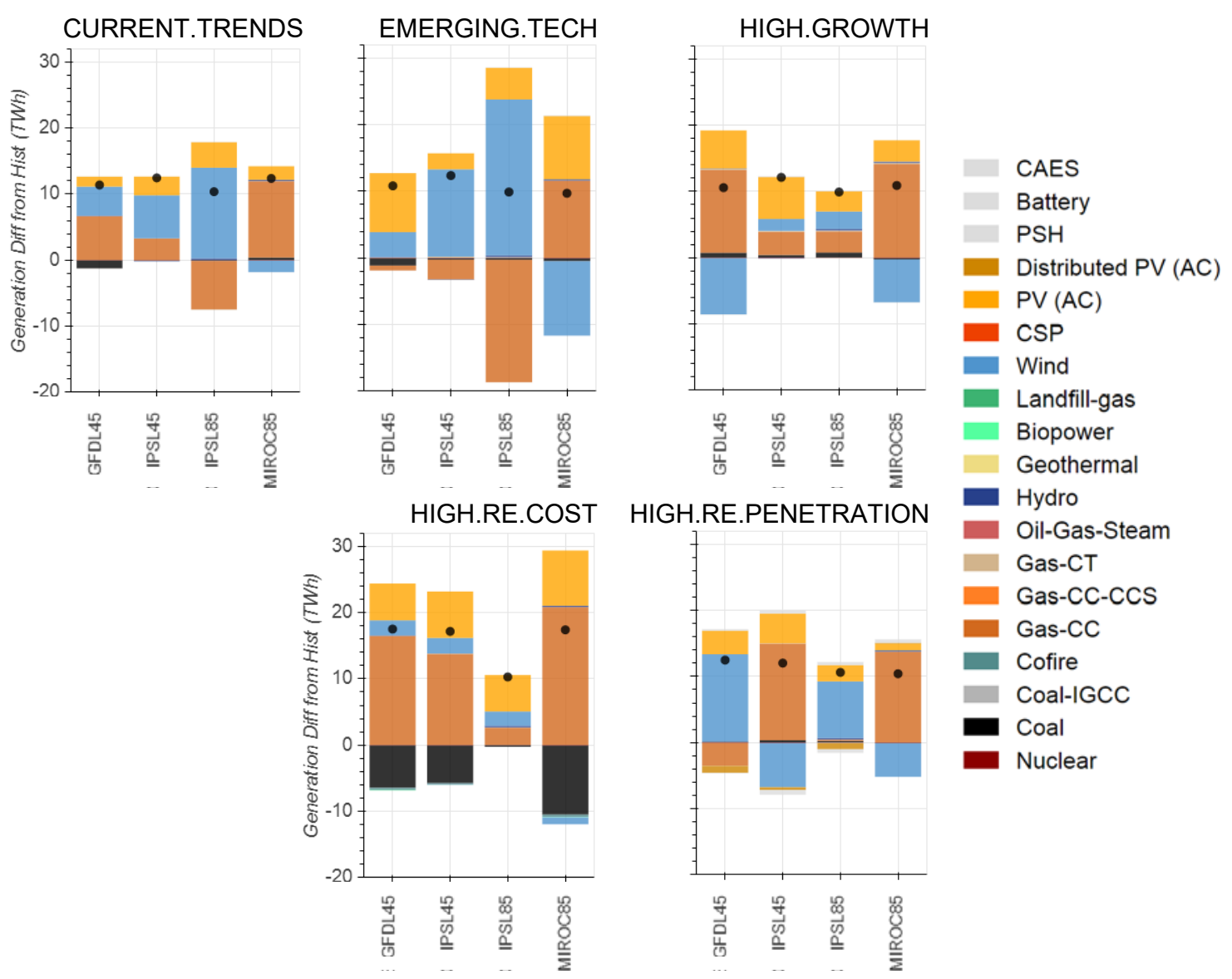

Figure 7. Climate impacts on ERCOT 2034 generation for each climate scenario relative to the corresponding electricity scenario without climate change impacts. Circles on plot represent net effect.

\subsection{Transmission Capacity}

Changes to the generation mix can correspond to changes in inter-BA transmission capacity needs, depending on where new generation assets are built, the status of existing constraints in transmission capacity, and their proximity to load. Figure 8 plots total inter-BA ERCOT transmission capacity over time for each scenario with historical climate conditions. Wind and PV growth can drive additional transmission capacity needs, with $6.7 \mathrm{GW}$ new transmission built in the HIGH.RE.PENETRATION.HIST scenario between 2018 and 2034. Scenarios with intermediate wind and PV growth expand transmission capacity by $1.4-2.4 \mathrm{GW}$ in this time period, while the HIGH.RE.COST.HIST scenario has no modeled transmission investments because it constructs primarily Gas-CC capacity through $2034 .^{1}$

\footnotetext{
${ }^{1}$ A real system would likely still require some transmission investment even for this case for intra-BA transmission. ReEDS transmission results are useful for comparing across scenarios but should not imply an absolute need for transmission investment.
} 


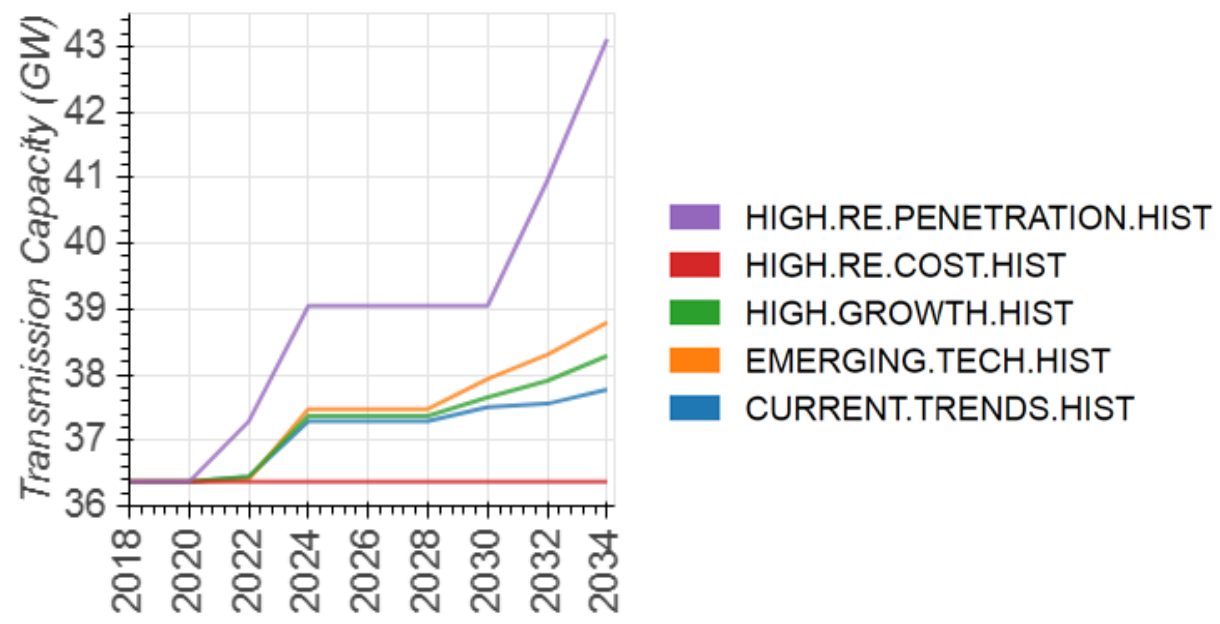

Figure 8. ERCOT transmission capacity over time in historical climate scenarios. Note: y-axis does not start at 0 .

Figure 9 describes how climate change affects transmission needs, plotting the difference between 2034 ERCOT transmission capacity in climate scenarios and the corresponding historical climate scenario. For the scenarios with intermediate transmission growth (CURRENT.TRENDS, EMERGING.TECH, HIGH.GROWTH), climate effects can increase transmission expansion up to about $1 \mathrm{GW}$, but this effect is inconsistent, particularly for the IPSL45 climate scenario. There are no climate impacts on transmission in HIGH.RE.COST, which does not invest in new transmission capacity under historical climate conditions. The HIGH.RE.PENETRATION scenario has the greatest variability in transmission impacts, ranging from a $1.0 \mathrm{GW}$ reduction to a $1.2 \mathrm{GW}$ increase. Transmission expansion is sensitive to climate impacts for this scenario because of the close competition between variable renewables, which additional transmission can complement, and natural gas-based generation, which can typically be deployed within a BA that needs it. Uncertain capacity effects shown in Figure 5 thus result in uncertain transmission impacts in the HIGH.RE.PENETRATION scenario. 

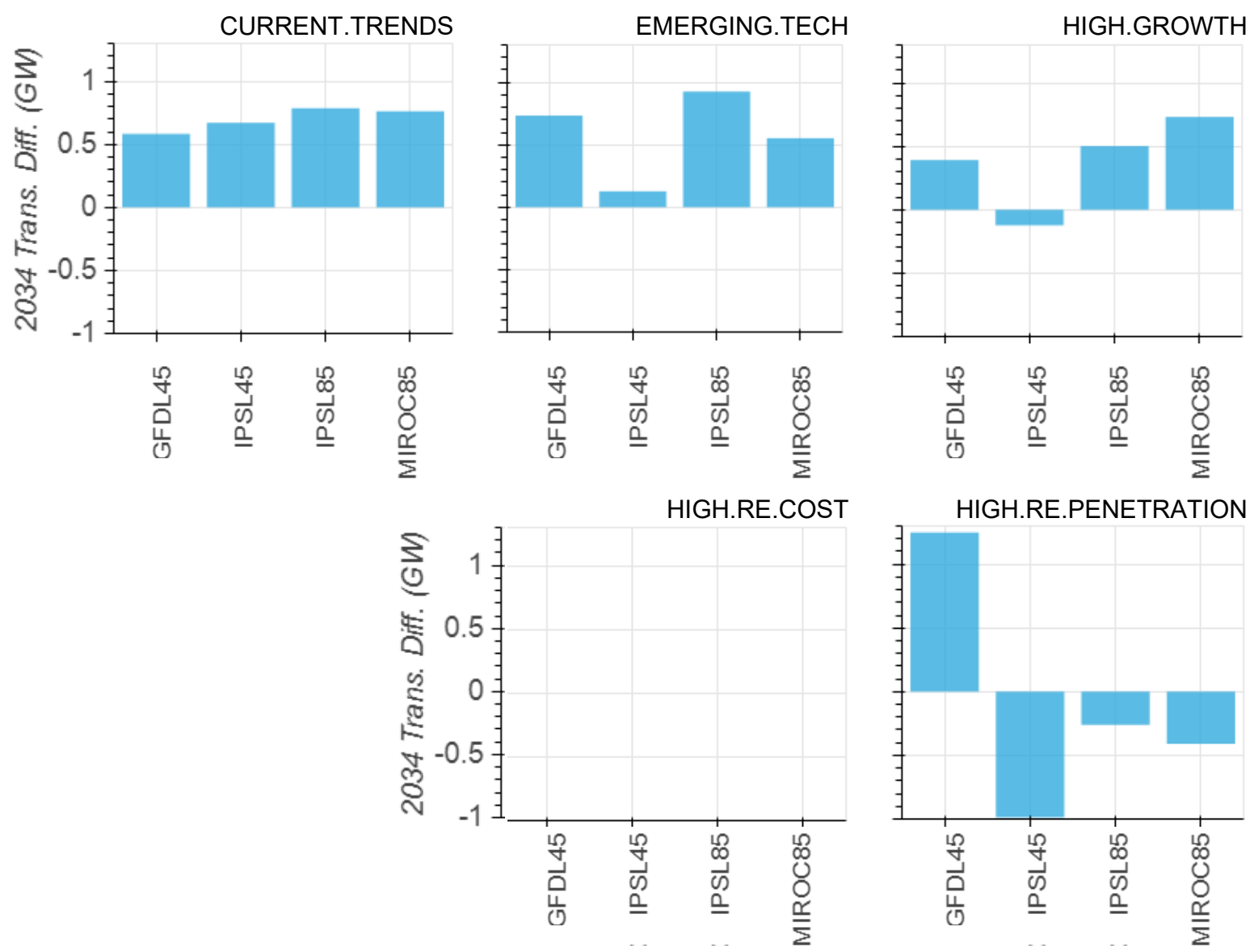

Figure 9. Change in 2034 ERCOT transmission capacity for climate impacts scenarios, relative to the corresponding historical climate scenario.

\subsection{Marginal and Total System Cost}

Differences in capacity expansion and generation between scenarios leads to differences in electric sector costs. One metric of cost, total system cost, considers cumulative investment and operating costs across the period of interest, 2018-2034 in this case. These costs, discounted at $7 \%$ per year to calculate a present value, are shown for each of the five historical climate scenarios in Figure 10. The present value costs demonstrate that higher electricity demand in the EMERGING.TECH and HIGH.GROWTH scenarios lead to higher costs relative to the CURRENT.TRENDS scenario, but the cost distribution between conventional (fossil and nuclear) and renewable electricity technologies is similar across these three scenarios. The HIGH.RE.COST scenario has higher total costs than CURRENT.TRENDS because higher assumed RE technology costs leads the model to increase natural gas usage, which dominates conventional fuel costs. Costs are also higher than in CURRENT.TRENDS for the HIGH.RE.PENETRATION scenario, where there is a larger share of renewable capital costs and a more noticeable contribution of transmission costs. However, costs shown in Figure 10 ignore any credit from PTC and ITC incentives, which are greater in the HIGH.RE.PENETRATION scenario and, if included, would likely substantially reduce the net-costs in that scenario. Further, these electric sector-only costs do not necessarily reflect the impacts on the broader energy sector or overall economy, which would have to be assessed with tools of a wider scope. Across all 
scenarios, 2018-2034 present value costs fall in the range \$211-\$226 billion 2018\$, for a maximum relative change of $7 \%$.

Figure 11 shows the incremental climate impacts on electricity system costs by taking the difference between each climate impacts scenario and the corresponding historical climate scenario. Across all scenarios, cumulative climate impacts on cost are $\$ 4-\$ 10$ billion (2-5\%) over 2018-2034. The consistent increase in total costs is driven by higher electricity demand from higher average temperatures, which requires additional capacity investments, and in some scenarios, fuel costs. Consistent trends across individual climate scenarios for each electricity scenario reflect differences in their temperature projections. For most scenarios, incremental costs are primarily capital costs for additional Gas-CC, Gas-CT, wind, and PV capacity. The major exception is the HIGH.RE.COST scenarios, which primarily use additional Gas-CC generation to respond to higher electricity demands and thus include a significant gas fuel cost component. In aggregate, climate impacts on cost are similar across the CURRENT.TRENDS, EMERGING.TECH, and HIGH.GROWTH scenarios. Cost impacts are greatest for the HIGH.RE.COST scenario, potentially revealing an economic vulnerability from maintaining a gas-dominated system. Conversely, climate impacts on cost are lowest for the HIGH.RE.PENETRATION system.

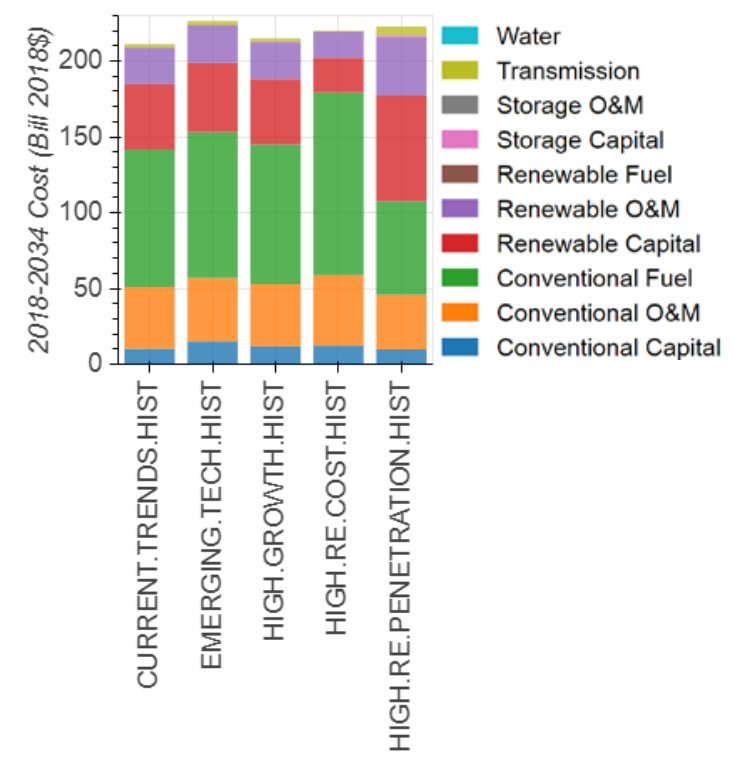

Figure 10. Net present value of total system investment and operating costs in 2018-2034 for historical climate scenarios. Conventional refers to fossil and nuclear. Water refers to water access purchases for new capacity. 

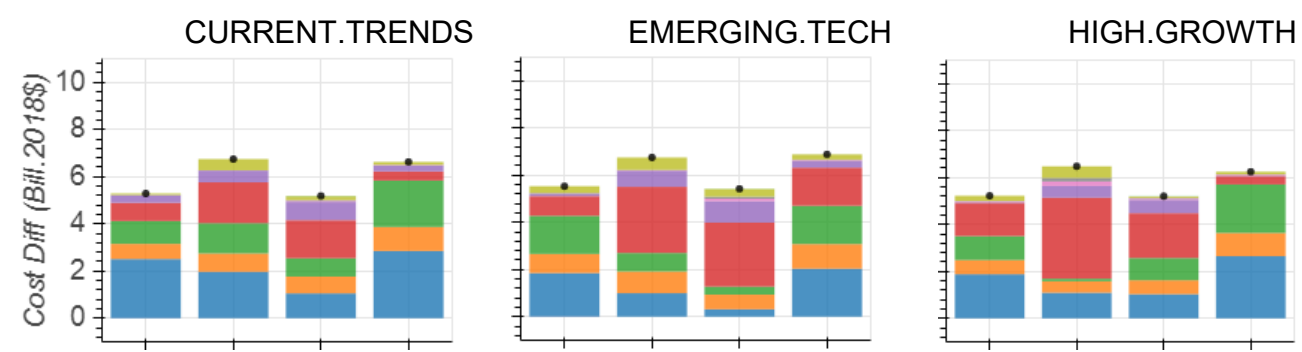

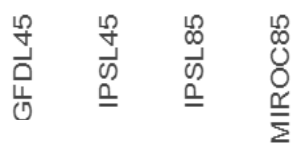

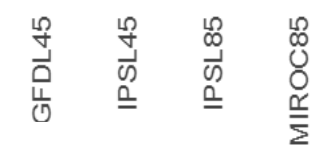

HIGH.RE.COST

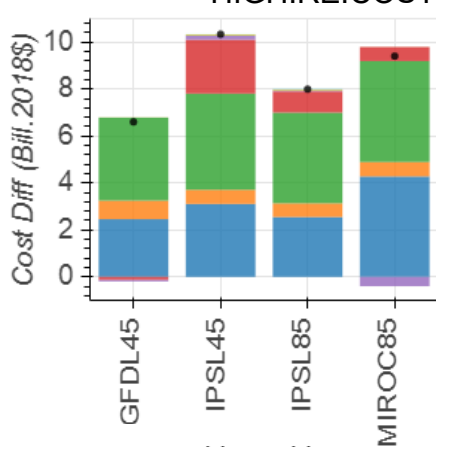

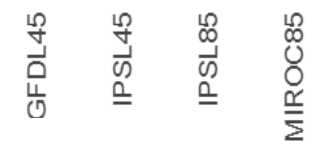
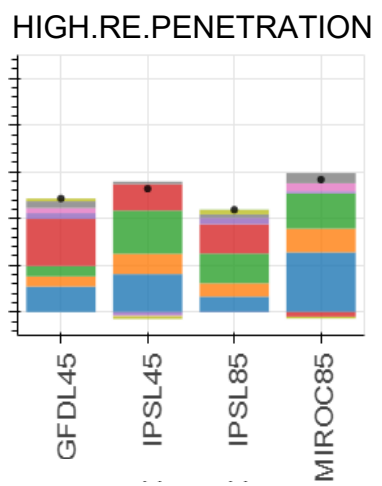

Water
Transmission

- Storage O\&M

Storage Capital

- Renewable Fuel

Renewable O\&M

Renewable Capital

- Conventional Fuel

Conventional O\&M

- Conventional Capital

Figure 11. The change in total system investment and operating costs in 2018-2034 in climate impacts scenarios relative to the corresponding historical climate scenario. Conventional refers to fossil and nuclear. Water refers to water access purchases for new capacity.

Marginal cost of electrical energy is another important metric compared in Figure 12 by plotting the average marginal energy cost across ERCOT in each year for each scenario. This metric is produced using the marginal "price" from the ReEDS supply-demand balance constraint, which is an indicator of competitive wholesale market prices. However, differences in model structure between ReEDS and real markets mean that these results should primarily be used for comparing across scenarios rather than for projecting future market prices.

Marginal cost results are driven primarily by electricity scenario specifications, not climate projections. For each electricity scenario, each of the five climate scenarios are clustered together, indicating that climate effects do not strongly influence marginal electricity costs. Marginal cost trajectories generally correspond to natural gas prices and the frequency that gasfired facilities are the marginal generators. That is why the HIGH.RE.COST scenarios, with higher gas usage and prices, have higher prices; while the HIGH.RE.PENETRATION scenarios, with much lower gas usage and corresponding higher usage of zero variable cost wind and solar resources have lower prices. 


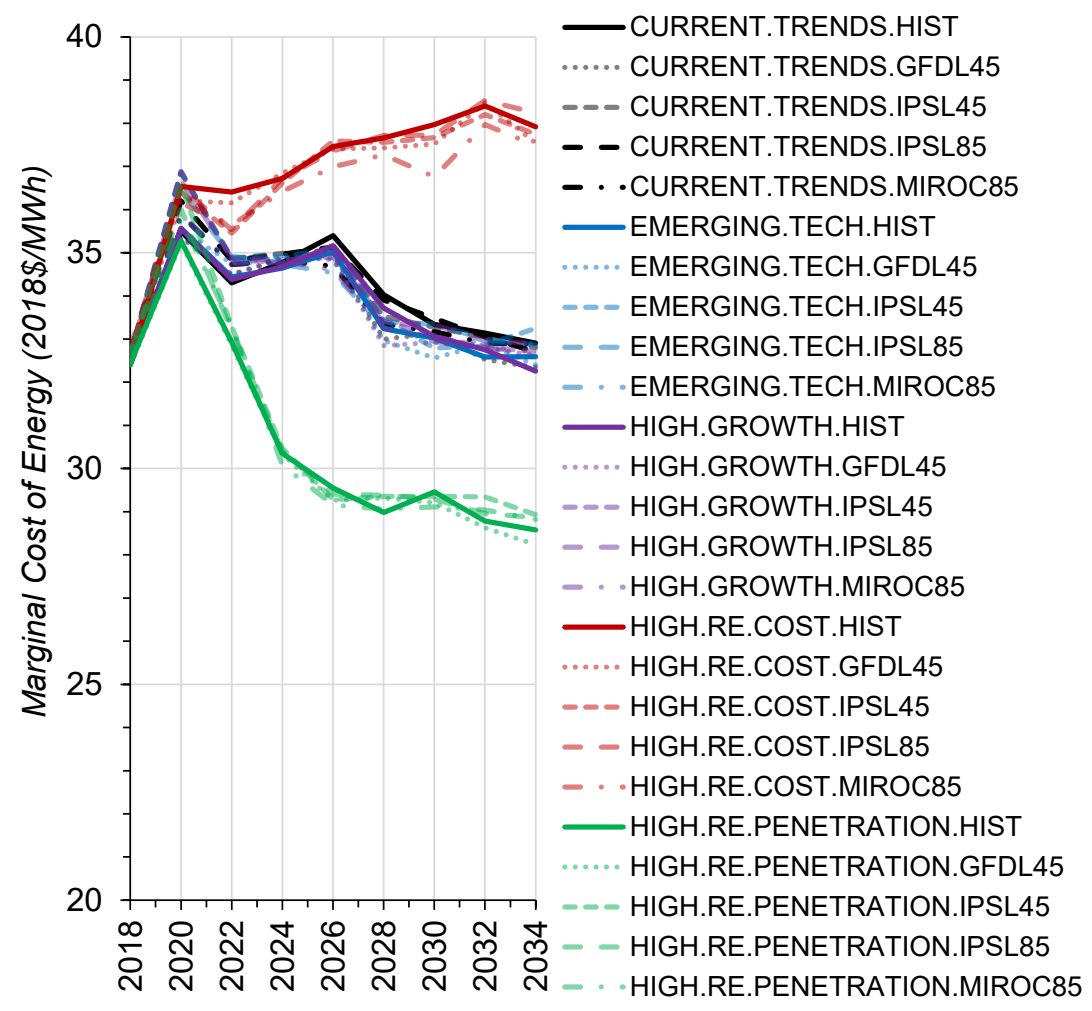

Figure 12. ERCOT-average marginal cost of electrical energy over time in all scenarios. This metric is the marginal price taken from the electricity supply-demand balance in ReEDS. Note that the $y$-axis does not start at 0 and costs are similar through 2020 because the capacity changes are largely prescribed in historic and current years.

\section{$3.4 \mathrm{CO}_{2}$ Emissions}

The environmental implications of climate impacts on the electric sector are also important to consider, particularly in a system like ERCOT where climate impacts are expected to increase electricity demand. Figure 13, however, demonstrates that through 2034, $\mathrm{CO}_{2}$ emissions do not vary greatly between climate scenarios for a given electricity scenario, with electricity scenario drivers being the primary determinant of future electricity system $\mathrm{CO}_{2}$ emissions. Annual $\mathrm{CO}_{2}$ emissions in the CURRENT.TRENDS scenario fall between $25 \%$ and $32 \%$ between 2018 and 2034, which is similar to the $24-28 \%$ reduction in the HIGH.GROWTH scenario. Higher demand growth in the EMERGING.TECH scenario leads to slightly higher $\mathrm{CO}_{2}$ than the other central scenarios, but emissions still fall 13-22\%. Alternative assumptions around RE technology have the biggest effect on $\mathrm{CO}_{2}$, with the gas-dominated HIGH.RE.COST scenarios increasing annual $\mathrm{CO}_{2}$ by $21-26 \%$ while the wind-dominated HIGH.RE.PENETRATION scenarios reduce $\mathrm{CO}_{2}$ by $63-68 \%$. The incremental climate impact on $\mathrm{CO}_{2}$ emissions thus only shifts the change in 2018-2034 emissions on the order of 4-9\% in these scenarios. This effect is expected to increase, however, as climate changes become larger beyond 2034. 


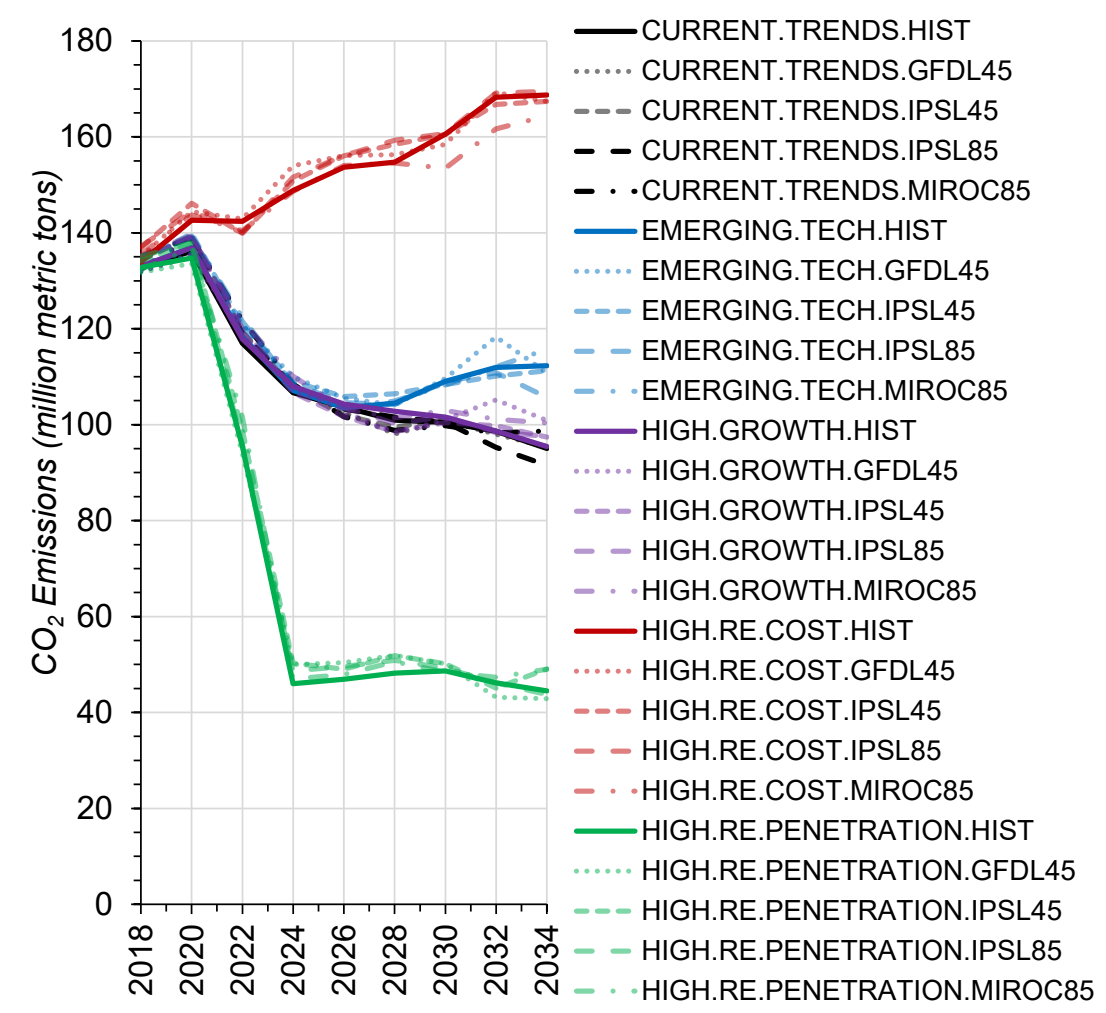

Figure 13. Electric sector $\mathrm{CO}_{2}$ emissions over time for all scenarios.

\section{Summary and Conclusions}

ERCOT generation and transmission capacity expansion is simulated through 2034 using a multi-model climate-hydrology-electricity framework that explores 20 future scenarios spanning a range of demand levels, generation mixes, and climate outcomes. When isolating the impacts of changing temperature and water availability on capacity expansion decisions, the most robust outcome is the need for additional generating capacity to satisfy higher peak and average electricity demand, which amounts to an additional 10.7-13.0 TWh of total demand in 2034 . This increased demand results in an additional 5-15 GW generating capacity to satisfy system energy and capacity requirements.

Climate impacts on the deployment of specific generation technologies are diverse and dependent on the underlying assumptions driving the future generation mix. All scenarios increase deployment of natural gas-based generating capacity to some extent, but the primary role of natural gas resources - either to provide energy to help meet electricity demand or capacity to serve planning and operation requirements - varies depending on the scenario. PV deployment is often higher due to the coincidence between PV resource and peak demand, but the effect of climate change on wind deployment is characterized by a higher degree of uncertainty. Uncertainty impacts on generation technologies are reflected, to some degree, in climate effects on transmission capacity. Some scenarios require additional transmission on the order of $1 \mathrm{GW}$, while others have minimal change or even less transmission capacity relative to corresponding scenarios under historical climate conditions. 
Additional generation and transmission investment and operation results in a $2-5 \%$ increase in the present value of cumulative system costs over the 2018-2034 period, or \$4-\$10 billion (assuming a 7\% discount rate). Incremental costs due to climate impacts are similar across most electricity futures; however, costs are higher in a future with less optimistic renewable energy cost projections, which is the expected outcome when assuming higher costs of any technology that the model tends to deploy. In this particular scenario, the outcome of higher-cost renewables is an increase in natural gas fuel usage in response to climate-impacted load, so the incremental cost is largely natural gas fuel expenditures Conversely, cost impacts are lower with favorable projections for renewable energy deployment due to low long-term operating costs associated with the higher share of zero variable cost wind and solar resources.

While climate change has measurable impacts on total system capacity needs and costs, the other chosen drivers of the electricity future have the largest impact on the overall generation mix. In addition, the marginal generation technology is also consistent across alternative climate conditions. As a result, climate effects do not substantially alter the marginal cost of energy, which is a proxy for the competitive wholesale electricity price. System-wide $\mathrm{CO}_{2}$ emissions are also relatively stable across climate scenarios for each electricity future. Electricity system drivers such as demand, technology costs, and policy dominate climate effects on these metrics through 2034.

While these scenarios do not necessarily represent bounds or a distribution all possible climateelectricity futures of the ERCOT system, they indicate that climate impacts on electricity demand and generation capacity are important to consider in planning future investments. While the detailed climate impacts presented in this analysis are uncertain and under some projections, modest, climate change is expected to accelerate towards midcentury and beyond, and the 2034 time horizon is relatively short for observing these effects. It could be important to consider climate impacts beyond 2034 for assets that will persist beyond that date. Within any time frame, a more comprehensive scenario analysis could also include expanded scenarios for technology costs (including utility-scale batteries), fuel prices, demand (including electrification effects), and policies. While climate and water effects do not drive all future electric sector outcomes, they are important to consider among other key system drivers for effective system planning. 


\section{References}

ABB Velocity Suite; 2017. http://new.abb.com/enterprise-software/energy-portfoliomanagement/market-intelligence-services/velocity-suite.

Allen, M., Fernandez, S., Fu, J. and M. Olama. 2016. "Impacts of climate change on sub-regional electricity demand and distribution in the southern United States." Nat. Energy 1:16103.

Auffhammer, M., Baylis, P., and C.H. Hausman. 2017. "Climate change is projected to have severe impacts on the frequency and intensity of peak electricity demand across the United States." Proc Natl Acad Sci 114:1886-1891. 10.1073/pnas.1613193114.

Averyt, K., Meldrum, J., Caldwell, P., Sun, G., McNulty, S., Huber-Lee, A., and N. Madden. 2013. "Sectoral contributions to surface water stress in the conterminous United States."

Environmental Research Letters 035046 (9pp).

Bartos, M.D. and M.V. Chester. 2015. "Impacts of climate change on electric power supply in the Western United States.” Nat. Clim. Change 5:748-52.

Bartos, M., Chester, M., Johnson, N., Gorman, B., Eisenberg, D., Linkov, I., and M. Bates. 2016. "Impacts of rising air temperatures on electric transmission ampacity and peak electricity load in the United States." Environ Res Lett 11.

Chuang, C.C. and D.C. Sue. 2005. "Performance effects of combined cycle power plant with variable condenser pressure and loading.” Energy 30(10):1793-1801.

Cohen, S.M., Becker, J., Bielen, D.A., Brown, M., Cole, W.J., Eurek, K.P., ... \& Jadun, P. 2019. Regional Energy Deployment System (ReEDS) Model Documentation: Version 2018. Golden, CO: National Renewable Energy Laboratory. NREL/TP-6A20-2023. https://doi.org/10.2172/1505935.

Cole, W.J. and N.M. Vincent. 2019. Historical Comparison of Capacity Build Decisions from the Regional Energy Deployment System (ReEDS) Model. Golden, CO: National Renewable Energy Laboratory. NREL/TP-6A20-71916. https://doi.org/10.2172/1505552.

Cole, W.J., Frazier, A., Donohoo-Vallett, P., Mai, T.T., and P. Das. 2018. 2018 Standard Scenarios Report: A US Electricity Sector Outlook. Golden, CO: National Renewable Energy Laboratory. NREL/TP-6A20-71913. https://doi.org/10.2172/1481848.

Dieter, C.A., Maupin, M.A., Caldwell, R.R., Harris, M.A., Ivahnenko, T.I., Lovelace, J.K., Barber, N.L., and K.S. Linsey. 2018. Estimated use of water in the United States in 2015. U.S. Geological Survey Circular 1441. https://doi.org/10.3133/cir1441.

Dirks, J.A., Gorrissen, W.J., Hathaway, J.H., Skorski, D.C., Scot, M.J., Pulsipher, T.C., Huang, M., Liu, Y., and J. Rice. 2015. "Impacts of climate change on energy consumption and peak demand in buildings: a detailed regional approach." Energy 79:20-32. 
DOE. 2016. Hydropower Vision: A New Chapter for America's 1st Renewable Electricity Source. Washington, D.C.: U. S. Department of Energy. Technical Report DOE/GO-1020164869.

DOE. 2019. GeoVision: Harnessing the Heat Beneath Our Feet. Washington, D.C.: U. S. Department of Energy.

Durmayaz, A. and O.S. Sogut. 2006. "Influence of cooling water temperature on the efficiency of a pressurized-water reactor nuclear-power plant." Int J Energy Res 30(10):799-810.

EIA. 2018. Annual Energy Outlook 2018 with Projections to 2050. Washington, D.C.:U.S. Energy Information Administration Office of Energy Analysis, U.S. Department of Energy.

“ESGF-LLNL - Home | ESGF-CoG.” n.d. Accessed July 12, 2021. https://esgfnode.1lnl.gov/projects/esgf-1ln1/.

Frazier, A.W., Marcy, C., and W. Cole. 2019. « Wind and solar PV deployment after tax credits expire: A view from the standard scenarios and the annual energy outlook." The Electricity Journal 32(8), 106637. https://doi.org/10.1016/j.tej.2019.106637.

Hempel, S., Frieler, K., Warszawski, L., Schewe, J., and F. Piontek. "A trend-preserving bias correction - the ISI-MIP approach.” Earth System Dynamics 2013;4(2):219-236. doi:10.5194/esd-4-219-2013.

Henry, C.L., and L.F. Pratson. 2016. "Effects of Environmental Temperature Change on the Efficiency of Coal- and Natural Gas-Fired Power Plants." Environ. Sci. Technol. 50:9764-9772.

Henry, C.L., and L.F. Pratson. 2019. "Differentiating the Effects of Climate Change-Induced Temperature and Streamflow Changes on the Vulnerability of Once-Through Thermoelectric Power Plants.” Environmental science \& technology 53(7), 3969-3976.

Ibrahim, S.M.A., Ibrahim, M.M.A., and S.I. Attia. 2014. "The impact of climate changes on the thermal performance of a proposed pressurized water reactor: nuclear-power plant." Int J Nucl Energy 2014:1-7.

ICF. 1995. "Potential Effects of Climate Change on Electric Utilities."

Jaglom, W.S., McFarland, J.R., Colley, M.F., Mack, C.B., Venkatesh, B., Miller, R.L., ... \& J.A. Martinich. 2014. "Assessment of projected temperature impacts from climate change on the US electric power sector using the Integrated Planning Model ${ }^{\circledR} . ”$ Energy Policy 73:524-539. https://doi.org/10.1016/j.enpol.2014.04.032.

Mai, T., Cole, W., and A. Reimers. 2019. "Setting cost targets for zero-emission electricity generation technologies." Applied Energy 250:582-92.

https://doi.org/10.1016/j.apenergy.2019.05.001. 
McFarland, J., Zhou, Y., Clarke, L., Sullivan, P., Colman, J., Jaglom, W. S., ... and G.P. Kyle. 2015. "Impacts of rising air temperatures and emissions mitigation on electricity demand and supply in the United States: a multi-model comparison." Climatic Change 131(1):111-125. https://doi.org/10.1007/s10584-015-1380-8.

Miara, A., Cohen, S.M., Macknick, J., Vorosmarty, C.J., Corsi, F., Sun, Y., Tidwell, V.C., Newmark, R., and B.M. Fekete. 2019. "Climate-Water Adaptation for Future US Electricity Infrastructure.” Environmental Science \& Technology https://doi.org/10.1021/acs.est.9b03037.

Miara, A., Vörösmarty, C. J., Macknick, J. E., Tidwell, V. C., Fekete, B., Corsi, F., and R. Newmark. 2018. "Thermal pollution impacts on rivers and power supply in the Mississippi River watershed." Environmental Research Letters 13(3):034033. doi.org/10.1088/1748-9326/aaac85.

Miara, A., Macknick, J. E., Vörösmarty, C. J., Tidwell, V. C., Newmark, R., and B. Fekete. 2017. "Climate and water resource change impacts and adaptation potential for US power supply.” Nature Climate Change 7(11):793. doi.org/10.1038/NCLIMATE3417.

Miara, A., and C.J. Vörösmarty. 2013. "A dynamic model to assess tradeoffs in power production and riverine ecosystem protection." Environmental Science: Processes \& Impacts 15 (6):1113.

NREL. 2018. 2018 Annual Technology Baseline. Golden, CO: National Renewable Energy Laboratory.

Reclamation. 2013. Downscaled CMIP3 and CMIP5 Climate and Hydrology Projections: Release of Downscaled CMIP5 Climate Projections, Comparison with preceding Information, and Summary of User Needs. Denver, CO: U.S. Department of the Interior, Bureau of Reclamation, Technical Services Center.

Roy, S.B., Chen, L., Girvetz, E.H., Maurer, E.P., Mills, W.B., and T.M. Grieb. 2012. "Projecting Water Withdrawal and Supply for Future Decades in the U.S. under Climate Change Scenarios." Environ. Sci. Technol 46 (5):2545-2556, DOI: 10.1021/es2030774.

Sathaye, J.A., Dale, L.L., Larsen, P.H., Fitts, G.A., Koy, K., Lewis, S.M., and A.F.P. de Lucena. 2013. "Estimating impacts of warming temperatures on California's electricity system." Glob Environ Chang 23:499-511. 10.1016/i.gloenvcha.2012.12.005.

Sovacool, B.K. and K.E. Sovacool. 2009. "Identifying future electricity-water tradeoffs in the United States." Energy Policy 37:2763-73

Steinberg, D.C., Mignone, B.K., Macknick, J., Sun, Y., Eurek, K., Badger, A., Livneh, B., and K. Averyt. 2020. "Decomposing supply-side and demand-side impacts of climate change on the US electricity system through 2050." Climatic Change 158:125-139.

https://doi.org/10.1007/s10584-019-02506-6

Sullivan, P., Colman, J., and E. Kalendra. 2015. Predicting the response of electricity load to climate change. Golden, CO: National Renewable Energy Lab. NREL/TP-6A20-64297. 
Taseska, V., Markovska, N., and J.M. Callaway. 2012. "Evaluation of climate change impacts on energy demand." Energy 48(1):88-95.

Tidwell, V.C, Moreland, B.D., Zemlick, K.M., Roberts, B.L., Passell, H.D., Jensen, D., Forsgren, C., Sehlke, G., Cook, M.A., King, C.W. and S. Larsen. 2014. "Mapping water availability, projected use and cost in the Western United States." Environmental Research Letters 9(6). doi:10.1088/1748-9326/9/6/064009.

Tidwell, V.C., Bailey, M., Zemlick, K.M. and Moreland, B.D., 2016. "Water supply as a constraint on transmission expansion planning in the Western interconnection." Environmental Research Letters 11(12):124001.

Turner, S.W.D., Yi, J., and S. Galelli. 2017. "Examining global electricity supply vulnerability to climate change using a high-fidelity hydropower dam model." Sci Total Environ 591:663-675.

Turner, S.W.D., Nelson, K., Voisin, N., Tidwell, V., Miara, A., Dyreson, A., Cohen, S., Mantena, D., Jin, J., Warnken, P., and S.-C. Kao. 2021. "A multi-reservoir model for projecting drought impacts on thermoelectric disruption risk across the Texas power grid." Energy 231:120892.

Van Vliet, M.T.H., Yearsley, J.R., Ludwig, F., Vögele, S., Lettenmaier, D.P., and P. Kabat. 2012. "Vulnerability of US and European electricity supply to climate change." Nat. Clim.

Change 2:676-81

Voisin, N., Dyreson, A., Fu, T., O'Connell, M., Turner, S.W.D., Zhou, T., and J. Macknick. 2020. "Impact of climate change on water availability and its propagation through the Western U.S. power grid." Applied Energy. 276:115467. 